\title{
Compensating clinical trial participants from limited resource settings in internationally sponsored clinical trials : A proposal
}

\section{Paul Ndebele $^{1}$, Joseph Mfutso-Bengo ${ }^{1}$, Takafira Mduluza $^{2}$}

1. Centre for Bioethics in Eastern and Southern Africa, CEBESA, College of Medicine, Malawi.

2. Department of Student Affairs, University of Zimbabwe, Zimbabwe

Corresponding author: Paul Ndebele, Centre for Bioethics in Eastern and Southern Africa (CEBESA), Department of Community Health, College of Medicine, Private Bag 360, Chichiri, Blantyre 3, Malawi Phone: +2651871 911, Email: pndebele@medcol.mw

\begin{abstract}
Trial participants from limited resource settings often are given very little or nothing in terms of compensation for time, inconvenience and risks as compared to their counterparts from developed countries. The reason that is often sited by researchers, ethics committees, and sponsors is the avoidance of undue inducements. We discuss the inherent conflict that may arise in trying to avoid undue inducement and in trying to minimize injustice in international research. We argue that research participants from both industrialized nations and those from limited resource settings should be compensated equally since they suffer the same burdens and equally contribute towards the study by contributing the same product - data. We make recommendations that acknowledge and address the existing injustice in the compensation of trial participants in international research.
\end{abstract}

\section{Introduction}

A significant amount of literature exists on the subject of compensating trial participants for participating in research,

1-5 however very little has been written specifically on the compensation of participants within international research, especially research that is sponsored by industrialized countries and is conducted in developing countries or is conducted in both developed and developing countries. Presently there is an increase in the amount of research being conducted in developing countries which is mostly sponsored by developed countries. Fears continue to be expressed in developing countries on the possibility of exploitation of individuals and communities who may be used as inexpensive sources of data in clinical trials since they are cheaper to compensate as compared to trial participants from developed countries. This paper focuses on the issues of fairness in compensating research participants in international research from the point of view of developing countries. We propose justice in decision making on compensation of research participants in both the developed and developing countries since trial participants from both settings share "equally" in both the burdens and benefits of research. Data from a participant in a developing country is as useful as data from a research participant from a developed country. Data from both developed and developing countries is collated in order to come up with conclusive findings. This therefore implies that equal weight should be given to all the trial participants within a study whether or not they are from a limited resource settings or from a developed countries.

The issue of compensating trial participants can be viewed from two levels; the micro level which focuses on the research

participant who directly participates in the research, and the macro level which focuses on communities or countries that participate in research and also includes the global situation - At the micro level, there is need to consider that both participants from both industrialized countries and limited resource settings are contributing equally towards the same study. They suffer the same burdens and hence they need to be compensated equally. Both participants from the two settings have to be paid for inconvenience, time spent, pain and have to receive reimbursements for other study related expenses.

\section{Compensation: a definition}

We define compensation in research as "something done to make up for losses or costs incurred in the course of participating in a study". Compensation covers payments for participation (time) as well as reimbursements for costs associated with participation in a clinical trial. ${ }^{6}$ Payments to research participants for participation in studies are not considered as benefits. Compensation is not always straight forward to calculate. Compensation that is easy to address includes reimbursements for meals, babysitting, and bus fare to and from the research site. Reimbursements involve refunding the trial participants for any resources they would have used or that they are expected to use in order to participate in a trial.e.g. transport and lunch. There are three categories of compensation payments that are often problematic and are difficult to calculate. These are payments for time, pain and inconvenience. Some trials require visits that last much longer than a normal visit to the health centre. In those circumstances, one may receive compensation for his time. Some studies require multiple blood draws, Xrays, pap smears and other uncomfortable procedures such that one has to be compensated for the discomforts if one consents to such procedures. Clinical trial participants may also receive compensation for taking on the risks of receiving an experimental medication, especially if it may not directly benefit them. $^{7}$ Individuals may also be compensated for their blood sample, tissues, or body fluids.

\section{Models for Compensating Research Participants}

Payments for time, inconvenience and risk are difficult to calculate because so many factors are involved which are both personal and economic. There are four basic models for compensating participants for trial participation: the market model, the wage payment model, the fair share model and the reimbursement model. With the market model, the laws of supply and demand determine how much a trial participant should be paid, whilst with the wage payment model compensation is based on the premise that the research participation is an unskilled labourer and the research participants are paid on the scale commensurate with that of an unskilled labourer. With the fair share model, research participants are compensated a fixed amount that is determined to be fair. With the reimbursement model, 
payment is only permitted to cover the participants' expenses such as food, travel and lost wages. The market model, the wage payment model and the fair share model, accommodate the use of payments to induce people to participate in research whilst the reimbursement model strictly deals with the costs to the participant associated with participation. ${ }^{8,9}$ The reimbursement model also does not have room to accommodate compensation for inconvenience, risk and pain.

\section{Calculating compensation}

In international research, calculating compensation levels becomes a very complex exercise that investigators, sponsors and ethics committees would rather not tackle. Compensating trial participants for time, pain and inconvenience is difficult to calculate since it is based on the value of an individual's time and the cost they attach to the pain and inconvenience. The value of an individual's time depends on several factors such as local economic conditions and individual personalities. What may be one person's due inducement may be another person's undue inducement. Whilst it is acknowledged that compensation for time, pain and inconvenience are difficult to calculate, it is generally agreed that trial participants need to be compensated for their time, pain, risks and other inconveniences. Compensating participants for their participation and serves as a means of appreciating the risks and inconveniences of participating in research since participation in research, represents some form of sacrifice.

During a workshop for investigators from various African Countries, the majority of investigators reported that in most internationally funded clinical trials being conducted in their countries, research participants amount an amount ranging between $\$ 3$ and $\$ 5$ as compensation for all costs associated with participation.' The reason that is often given by investigators, sponsors and ethics committees for this is to avoid undue inducement for participants from limited resource settings. A $\$ 100$ compensation may be regarded as appropriate and non-coercive in a developed country setting and yet it represents several months' earnings for someone working in a developing country. This illustration presents a realistic conflict between avoiding undue inducement in limited resource settings and in developed countries.

Situations do exist where individuals participate in risky studies if high amounts of money are offered particularly if the large sums of money can solve financial problems. This situations do also developed countries where the term "professional research subject" has been coined to describe people who depend on participating in clinical trials for survival. Such persons benefit from the cash that is offered as compensation for participation. College students and the homeless are well known to be a very good source of research participants in developed country settings because of their urgent need for cash. ${ }^{10-14}$

In a study conducted among clinical trial participants in Kenya, respondents indicated that monetary compensation for time, inconvenience and risks was necessary and they indicated that they could use the cash to buy other life sustaining requirements such as antiretroviral drugs. Some participants even indicated that since they had no other sources of income, the cash could prevent them from engaging in risky activities such as prostitution. Some participants even suggested that researchers can compensate them using other means such as hard goods, foodstuffs or donations to local institutions and supporting organizations. Other respondents viewed their participation in terms of assisting the researchers to do their work. They therefore thought that it was only fair for participants to be compensated for participating in the researchers' studies. In the same study, some leading to risky behaviours such as consumption of alcohol.$^{15}$ Such fears reflect a conflict between the need to be fair to the trial participant and the need to avoid harm to the participant. This study highlights that research, besides providing new evidence, can also play the additional role of improving people's standard of living.

Sponsors and investigators need to realize that future access to individuals and communities lies with the preceding research conducted using those individuals and within those communities. Researchers need to realize that the amount of time that is spent by participants could be spent doing other beneficial things such as tending domestic animals, weeding crops or gathering fire wood. Most participants willing to be involved in clinical trials are women who have additional responsibilities such as taking care of children, gardens, and household duties

Several investigators from various African countries also reported that some participants are now aware of the disparity that exists in compensating them for their participation. The investigators further reported that some people are now refusing to participate in studies which do not compensate them for their participation are becoming common and participants are beginning to request for higher amounts for compensation. ' Locally sponsored research usually does not offer levels of compensation that are equal to those offered by internationally sponsored research due to the limited resources set aside for health research. This has led to deterioration in the quality of locally sponsored research as a result of the unwillingness of individuals to participate in such studies in favour of the better paying internationally funded trials. It is also possible that once participants become aware that they are being paid inappropriately less in comparison to their counterparts in industrialized nations, they may develop this same attitude even towards internationally sponsored trials.

\section{Recommendations}

In trying to strike a balance between the need to avoid undue inducement and the need to avoid injustice in the way trial participants from limited resource settings and those from developed countries are compensated, we suggest that compensation can be in different forms such as food, hard goods and even health care. Compensation in the form of health care can include comprehensive follow-up and provision of treatment. This may even be extended to the period after the trial. Compensation may also be provided through providing care for other nonstudy illnesses discovered during the clinical trials. Such care needs to be extended to communities where possible, so that high quality care offered through trial sites, may not be viewed as an undue inducement. This proposal will also assist sponsors and investigators in avoiding the difficulties surrounding the issue of dealing with cash in compensating trial participants. The issue of provision of ancillary care continues to be debated and there is a significant amount of 
literature covering the debates. ${ }^{16-20}$

Some researchers have been quick to point out that their role is not to improve standards of living for participants, but they need to realize that without those people who volunteer, there would be no clinical trials. Some researchers have suggested that the improvement of people's living conditions is the duty of donor agencies and not research sponsoring agencies. They have therefore suggested exchange programmes and consultations as a way forward. ${ }^{21}$ We propose too that in the interest of protecting locally funded research, some of the benefits as well as compensatory payments from internationally sponsored research may be converted into community benefits such as supporting clinics, electrifying community centres and schools, installation of boreholes or piped water, or engaging in other community projects which promote good health. We would even go as far as encouraging countries to come up with ways of raising resources from international research grants that can then be used to support local research as well as research institutions. Funds from research grants may also be used in technology transfer and in training and adequately remunerating personnel from resource limited settings This may reduce the current brain drain in favour of the developed countries and may also reduce the exportation of specimens to developed countries "for further analysis", whilst ultimately improving the capacity of developing countries to conduct research that directly addresses their own needs.

Another mechanism of ensuring that locally funded research trials do not suffer at the hands of internationally funded research, is to set levels of compensation and incentives that need to be adhered to for both locally and internationally funded trials. A certain percentage of the budget for internationally funded trials can then be diverted to other health promotion activities or programmes for the communities participating in the trials. In response to this proposal, some researchers have been quick to point out that it is not proper to use research funds for health promoting activities that are not related to the study being conducted. However, research is supposed to contribute towards improvements in health and this can be achieved in various ways. Other researchers have expressed fears that implementing such alternatives would be very complex and would require a substantial investment at the beginning. ${ }^{22}$ We argue that a major investment is necessary to change the mind-set of researchers and sponsors -so they realize there is injustice in the compensation of trial participants from limited resource settings.

The involvement of communities from limited resource settings in research as well as the offer of community benefits, should not serve as a way of shifting bias from patient level decision making towards institutional or community decision making. This simply is the addition of an additional layer of protection for vulnerable individuals. At the end of the day, studies do not deal with communities but with specific individuals within the community who have to make individual decisions. Community decisions such as community refusals can be made at community level through the communities, their leaders and also through the ethics committees. Refusals by communities assist in protecting vulnerable individuals within those communities. If the results from the study will not be applicable to the community nor the individuals taking part in the study, then no level of community compensation can be justifiable.

In our opinion, health research should play a part in redressing the current global imbalances by participating in the global processes of re-distribution of resources. Channelling of resources to developing countries for various initiatives including community development efforts, will avoid exposing individual participants to undue inducement. Community benefits can contribute to all the individuals within that community. The research and ethics committees (RECs) in developing countries can play an important role by addressing the issue of compensation and advising investigators appropriately. We suggest that RECs should negotiate on behalf of their communities for fair compensation. RECs should ensure that before granting permission for any study, they have critically looked at the population the participants will be drawn from, the amount of compensation being offered, and the capacity building efforts proposed at institutional, community and or national level. .

\section{Conclusion}

Individual, community and national compensation for participation in any research is ethical and that compensation should not only be in monetary terms but can also take other forms such as food and treatment follow-up. At the national level, compensation may come in the form of technology transfer, scientific, technical and medical training, installation and ongoing maintenance of infrastructure such as laboratories, clinics, libraries and other facilities. We also argue that research ethics committees should negotiate compensation and community benefits for their communities. Ethics committees in limited resource settings need to go beyond the question of whether payments constitute an undue inducement. They should consider whether the payment is fair considering the risks, inconveniences and pain that the research participants has to undertake absorb, and also consider the time the participant could have spent performing other duties.

\section{References}

1. Fry C \& Dwyer R. (2001). For love or money? An exploratory study of why injecting drug users participate in research. Addiction. 96(9):13191325

2. Ripley E, Macrina F, Markowitz M, Byrd L. To pay or not to pay: How to determine participant payment for a clinical study. Journal of Clinical Research Best Practices.. Vol 4. No. 3 March 2008. Available at :www.firstclinical.com [Accessed 10/05/2008]

3. Deren S, Stephens R, Davis WR, Feuchet TE, Tortu S. (1995) The impact of providing incentives for attendance at AIDS prevention session. Public Health Rep 109(4):548-54

4. Dickert, N., Grady C. What's the price of a research subject? Approaches to payment for research participation. New England Journal of Medicine 1999, 341(3), 198-203

5. Grady C, Dickert N, Jawetz T, Gensler G, Emanuel E. An analysis of U.S. practices of paying research participants; Contemp Clin Trials. 2005 Jun;26(3):365-75

6. Mcguire-Dunn C. and G. Chadwick, Protecting study volunteers in Research: A manual for investigative sites (Boston; Center Watch, Inc, 1999), 52-54

7. U.S. Food and Drugs Administration (FDA), "Basic answers and questions about clinical trials". Available at www.fda.gov/oashi/ clinical trials/clintrialdoc.html [Accessed :25 March 2007]

8. Amdur R. Institutional Review Board Member handbook (Massachusetts; Jones and Bartlett Publishers, 2003), 105-112

9. Report on the Proceedings of the Advanced Workshop on Research 
Ethics for investigators hosted by AMANET at Regency Park Hotel, Dar Es Salaam from 23-27 June 2008

10. Goldenberg, L.R. Owens, E.F, Pickar J,. Recruitment of Research Volunteers, Methods, Interest, and Incentives. The Journal of Chiropractic Education. 2007 Spring; 21(1): 28-31.

11. Gerstein LH, Wilkeson DA, Anderson H. Differences in motivations of paid versus non-paid volunteers. Psychol Rep. 2004;94:163-75

12. Grant RW, Sugarman A. Ethics in human subjects research: do incentives matter? J Med Philos. 2004;29:717-38.]

13. Grady C. Payment of clinical research subjects. J Clin Invest. 2005;115:1681-87

14. Russell ML, Moralejo DG, Burgess ED. Paying research subjects: participants' perspectives. J Med Ethics. 2000;26:126-30

15. Shaffer, D.N.Yebei, V.N. Ballidawa J.B. "Equitable treatment for HIV/AIDS clinical trial participants: a focus group study of patients, clinician researchers, and administrators in Western Kenya," Journal of Medical Ethics 2006;32;55-60

16. Richardson HS, Belsky L. The ancillary-care responsibilities of medical researchers. Hastings Cent Rep 2004;34: 25-33
17. Belsky L, Richardson HS (2004) Medical researchers' ancillary clinical care responsibilities. Brit Med J 328: 1494-1496

18. Tarantola D, Macklin R, Reed Z, Osmanov S, Stobie M, et al. (2007) Ethical considerations related to the provision of care and treatment in vaccine trials. Vaccine 25: 4863-4874

19. Richardson HS (2007) Gradations of ancillary-care responsibility for HIV-AIDS in developing countries. Am J Pub H 97: 1956-1961

20. Dickert N, DeRiemer K, Duffy PE, Garcia-Garcia L, Mutabingwa TK, et al. (2007) Ancillary-care responsibilities in observational research: Two cases, two issues. Lancet 369: 874-877

21. Schatz G.S. "International Research: Capacity, Compensation, and Community" Medical Humanities Report, Summer 2006. Available at : http://bioethics.msu.edu/mhr/06summer/InkLinks.htm [Accessed :13 November 2006]

22. Birbeck G.L. "Challenges in implementing community compensation" Medical Humanities Report, Summer 2006. Available at : http:// bioethics.msu.edu/mhr/06summer/InkLinks.htm [Accessed: 13 November 2006]

\section{Medical Council of Malawi Continuous Professional Development}

From May 2008 all qualified medical and dental practitioners are required to obtain $50 \mathrm{CPD}$ points in order to renew their license

\section{PUBLISH AN ARTICLE WITH MALAWI MEDICAL JOURNAL AND OBTAIN 10 POINTS}

under CPD code C: publications in reference journal as principal or co-author contribute 10 points

CPD diaries are available in the MMJ Office in the Microbiology Building at the College of Medicine, Mahatma Gandhi Campus, Blantyre

for more info:

email:mmj@medcol.mw

tel/fax: 01878524 